\title{
Preoperative PET/CT score can predict complete resection in advanced epithelial ovarian cancer: a prospective study
}

\author{
Bingxin Gu ${ }^{1,2,3,4 \#}$, Lingfang Xia ${ }^{2,5 \#}$, Huijuan $\mathrm{Ge}^{2,6}$, Shuai Liu ${ }^{1,2,3,4}$ \\ ${ }^{1}$ Department of Nuclear Medicine, Fudan University Shanghai Cancer Center, Shanghai 200032, China; ${ }^{2}$ Department of Oncology, Shanghai \\ Medical College, Fudan University, Shanghai 200032, China; ${ }^{3}$ Center for Biomedical Imaging, Fudan University, Shanghai 200032, China; ${ }^{4}$ Shanghai \\ Engineering Research Center of Molecular Imaging Probes, Shanghai 200032, China; ${ }^{5}$ Department of Gynecological Oncology, ${ }^{6}$ Department of \\ Pathology, Fudan University Shanghai Cancer Center, Shanghai 200032, China
}

"These authors contributed equally to this work.

Correspondence to: Shuai Liu. Department of Nuclear Medicine, Fudan University Shanghai Cancer Center, No. 270 Dongan Road, Shanghai 200032, China. Email: elaine_liu87@163.com.

Background: To assess the ability of preoperative positron emission tomography/computed tomography (PET/CT) scans to predict postoperative residual disease in advanced epithelial ovarian cancer (AEOC).

Methods: Thirty-one women with suspected AEOC were enrolled in our prospective study before surgery from July 2016 to December 2017. Complete resection was determined as no residual disease (R0) after surgery. A PET/CT scan was obtained within 2 weeks before surgery in our hospital. The PET score was the sum of each score of the radiological criteria from Suidan's model. The correlations between the PET score and tumor burden and surgical complexity were evaluated by Pearson correlation analysis. T-test or Fisher's exact test was used to compare differences in the variables between the complete and incomplete resection groups. Receiver operating characteristic (ROC) curve analysis was performed to assess the accuracy of the PET score for predicting complete postoperative resection.

Results: The median [range] of PET score was 2 [0-8], and the PET score in 20 (65\%) patients was less than 3. Complete resection was achieved in 11 (35.5\%) patients after surgery, including 10 (90.91\%) with low PET scores and only 1 (9.09\%) with a high score. The PET score had a significant positive correlation with tumor burden [Eisenkop: $\mathrm{r}=0.603, \mathrm{P}<0.001$; peritoneal cancer index $(\mathrm{PCI})$ : $\mathrm{r}=0.522, \mathrm{P}=0.003$ ] but not with surgery complexity (Aletti: $\mathrm{r}=0.291, \mathrm{P}=0.113)$. Patients with lower PET scores $(\mathrm{P}=0.046)$ and tumor burdens (Eisenkop: $\mathrm{P}=0.013$; PCI: $\mathrm{P}=0.012$ ) had higher rates of complete resection. The PET score and tumor burden were effective for predicting complete resection. The $\mathrm{AUC}_{\mathrm{PET}}, \mathrm{AUC}_{\mathrm{Eisenkop}}$, and $\mathrm{AUC}_{\mathrm{PCI}}$ were 0.797 (95\% CI: 0.633-0.961, P=0.01), 0.847 (95\% CI: 0.707-0.988, P=0.003), and 0.811 (95\% CI: $0.653-$ $0.969, \mathrm{P}=0.007)$, respectively. However, surgery complexity was not useful for assessing complete resection.

Conclusions: The preoperative PET score can noninvasively reflect tumor burden and helps predict complete resection after surgery in AEOC patients.

Keywords: Positron emission tomography score (PET score); complete resection; Suidan model; advanced epithelial ovarian cancer (AEOC)

Submitted Jul 21, 2019. Accepted for publication Feb 18, 2020.

doi: 10.21037/qims.2020.02.19

View this article at: http://dx.doi.org/10.21037/qims.2020.02.19 


\section{Introduction}

Ovarian cancer (OC) is the leading cause of gynecologic cancer-related death among women, with an estimated 22,500 deaths per year in China (1) and 151,900 deaths worldwide (2). The primary treatment is debulking surgery followed by platinum- and taxane-based adjuvant chemotherapy $(3,4)$. However, approximately half of the patients will recur within 16 months after primary treatment (5). The absence of residual tumors after primary debulking surgery leads to the best prognosis among advanced epithelial ovarian cancer (AEOC) patients (6-9). However, complete tumor resection is not always possible in patients (10). Therefore, finding reliable methods for predicting residual lesions before surgery is necessary for choosing patients suitable for optimal debulking to guide further individual treatment.

Many predictive models, such as clinical characteristics, diagnostic imaging, and laparoscopic findings, have been established to identify those AEOC patients who are likely to benefit from surgery (11-18). Due to its noninvasiveness, convenience, and cost-effectiveness, radiological imaging has become more prevalent in clinical practice for predicting cytoreducibility (12-18). Suidan et al. (16) proposed a computed tomography (CT)-based predictive model containing 8 quantitative radiological criteria that showed high accuracy with an area under the curve (AUC) of 0.694 for predicting complete cytoreduction in a prospective nonrandomized multicenter trial.

Therefore, in our previous triage prospective research, we first verified the external validity of this model (19). However, we found that this radiological model failed to predict complete resection, likely because we mixed CT and positron emission tomography/CT (PET/CT) scans together for analysis in our study. Numerous studies have reported that PET/CT displays the best performance in retreatment staging and the evaluation of distant ovarian carcinoma metastases compared with ultrasonography, CT, and magnetic resonance imaging (MRI) (20-23). Therefore, we aimed to confirm the external validation of Suidan's model using PET/CT scans and to identify the feasibility of predicting postoperative residual disease in AEOC.

\section{Methods}

\section{Patients}

This study was approved by the Committee at Fudan
University Shanghai Cancer Center (FUSCC), and informed consent was obtained from all enrolled patients. Patients with suspicious AEOC [International Federation of Gynecology and Obstetrics (FIGO) stages III and IV] at our institution were enrolled in this prospective study. All patients enrolled in our study did not receive any treatment before surgery. A preoperative PET/CT scan was performed within 2 weeks before treatment in our hospital. Patients were excluded from our study if they were confirmed with other types of OC or other malignancies according to pathology or if they first received neoadjuvant chemotherapy after preoperative evaluation. A total of 40 patients with suspected AEOC were enrolled from our hospital between July 2016 and December 2017. However, among these patients, 1 was ovarian tuberculosis, 2 were metastatic tumors, and 6 were non-AEOC patients. Finally, 31 patients were proven to have AEOC after surgery and were included in this analysis. The data including demographics, preoperative cancer antigen 125 (CA125) level, intraoperative findings, and surgical outcomes, were collected.

\section{PET/CT protocol}

2-Deoxy-2-( $\left({ }^{18} \mathrm{~F}\right)$ fluoro-D-glucose $\left({ }^{18} \mathrm{~F}-\mathrm{FDG}\right)$ was produced automatically by cyclotron (Siemens CTI RDS Eclipse ST, Knoxville, TN, USA) using the Explora FDG $_{4}$ module in our center, and the radiochemical purity was over $95 \%$. All patients fasted at least $4 \mathrm{~h}$ before ${ }^{18} \mathrm{~F}$-FDG $\mathrm{PET} / \mathrm{CT}$ imaging. Venous blood glucose levels were maintained under $10 \mathrm{mmol} / \mathrm{L}$. After injecting $7.4 \mathrm{MBq} / \mathrm{kg}$ $(0.2 \mathrm{mCi} / \mathrm{kg}){ }^{18} \mathrm{~F}-\mathrm{FDG}$, patients were kept quietly for approximately $1 \mathrm{~h}$. Images were obtained on a Siemens biograph 16HR PET/CT scanner (Knoxville, TN, USA). The transaxial intrinsic spatial resolution was $4.1 \mathrm{~mm}$ (full-width at half-maximum) in the center of the field of view, and the axial field width was $16.2 \mathrm{~cm}$ for image scanning. The data acquisition procedure was as follows: unenhanced low-dose CT scanning (tube voltage: $120 \mathrm{kV}$, tube current: $80-250 \mathrm{~mA}$, pitch 3.6, rotation time $0.5 \mathrm{~s}$ ) from the proximal thighs to the head was first performed. Subsequently, a PET emission scan using a three-dimensional acquisition mode with a matrix size of $168 \times 168$ was obtained. The acquisition time was $2-3 \mathrm{~min}$ per table position. PET image data sets were iteratively reconstructed by applying CT data for attenuation correction (8 subsets, 4 interactions), and the coregistered 


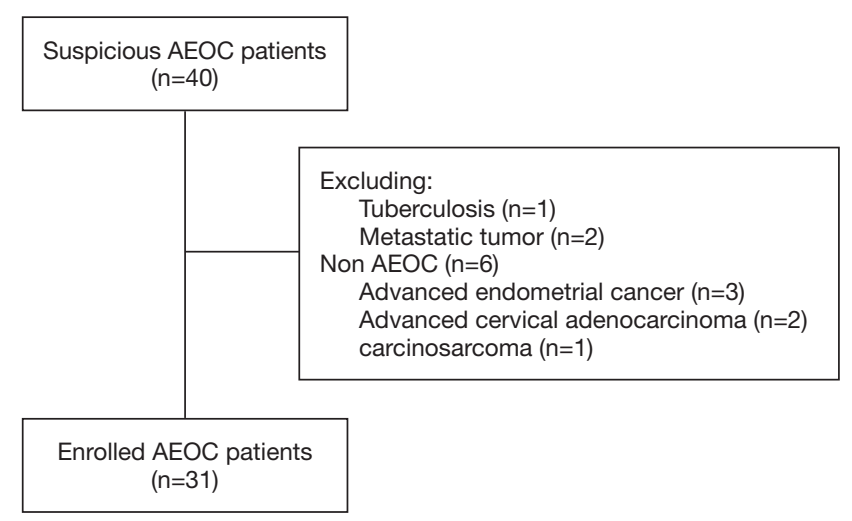

Figure 1 COSORT diagram of all enrolled patients.

images were displayed on a workstation.

\section{Imaging interpretation and PET score}

The images were reviewed and manipulated in a multimodality computer platform (Syngo, Siemens, Knoxville, Tennessee, USA). The standardized uptake value (SUV) of ovarian tumor was calculated with the following formula: [decay-corrected activity $(\mathrm{kBq}) /$ tissue volume $(\mathrm{mL})] /\left[\right.$ injected ${ }^{18} \mathrm{~F}$-FDG activity $(\mathrm{kBq}) /$ body mass $(\mathrm{g})]$. SUVmax was the maximum of SUV and was automatically produced by drawing a contour of the ovarian tumor large enough to encase the tumor in the axial, coronal, and sagittal PET images. The kidneys, ureters, and urinary bladder were manually subtracted to ensure the correct SUV.

Two experienced nuclear medicine physicians analyzed and interpreted all PET/CT images independently according to clinical index and image performance. A consensus was reached in the case of a discrepancy. Eight quantitative criteria based on Suidan's model (16) were recorded, including lesions in the porta hepatis/ gastrohepatic ligament (score $=1$ ), splenic hilum/ligaments (score $=1$ ), retroperitoneal lymph nodes above the renal hilum (including supradiaphragmatic, score $=1$ ), diffuse small bowel adhesions/peritoneal thickening (score $=1$ ), gallbladder fossa/liver intersegmental fissure (score $=2$ ), lesser sac (score $=2$ ), the presence of abdominal ascites (moderate-severe, score $=2$ ), and root of the superior mesenteric artery $($ score $=4)$. The PET score was the sum of each PET/CT criteria score. The patients were dichotomized by a PET score of 2 into low and high groups for further analysis (19).

\section{Intraoperative data}

During cytoreduction, the Aletti score (24) was used to rank surgical complexity, and the Eisenkop (25) and peritoneal cancer index (PCI) scores (26) were used to assess the tumor burden. The Aletti, Eisenkop, and PCI scoring criteria are shown in Figures S1-S3, respectively. The degree of surgical complexity and tumor burden were ranked according to earlier reports (24-26). R0 was defined as no macroscopic residual disease after surgery. R1 and R2 were defined as a macroscopic residual disease with a maximal diameter of $<1 \mathrm{~cm}$ and $\geq 1 \mathrm{~cm}$, respectively. Postoperative residual disease achieving $\mathrm{R} 0$ was defined as complete resection, while others were defined as incomplete resection.

\section{Statistical analysis}

Statistical analyses were conducted using SPSS statistical software (version 21.0; IBM Inc., New York, NY, USA). Frequencies with percentages were used to describe categorical variables, and medians with ranges were used for continuous variables. Pearson's correlation analysis was performed to calculate the correlations between PET score and intraoperative conditions (tumor burden and surgical complexity). The $t$-test was used to compare statistical differences in variables between the complete and incomplete resection groups. Fisher's exact test was further performed when $\mathrm{P}<0.05$ in the $t$-test. A receiver operating characteristic (ROC) curve was used to assess the ability of the PET/CT parameters and intraoperative variables to predict complete resection. The AUC values were used as an indicator for predictive accuracy. The AUC of the variable was noted as the $\mathrm{AUC}_{\text {variable. }}$. All statistical tests were two-sided, and $\mathrm{P}<0.05$ was considered statistically significant.

\section{Results}

\section{Patient characteristics}

From July 2016 to December 2017, a total of 31 patients with AEOC who underwent preoperative PET/CT imaging were eligible for inclusion, and the CONSORT diagram is shown in Figure 1. The patient characteristics are summarized in Table 1 . The median age was 57 years. The majority (64.5\%) of women had stage IIIC according to FIGO staging, and $93.5 \%$ of patients had serious OC. 
Table 1 Patient characteristics $(n=31)$

\begin{tabular}{|c|c|}
\hline Characteristics & Value \\
\hline Age (years) & 57 [38-76] \\
\hline \multicolumn{2}{|l|}{ FIGO stage } \\
\hline IIIA/B & $2(6.5 \%)$ \\
\hline IIIC & $20(64.5 \%)$ \\
\hline IV & $9(29.0 \%)$ \\
\hline \multicolumn{2}{|l|}{ Histology } \\
\hline Serous & $29(93.5 \%)$ \\
\hline Endometrioid/clear cell & $2(6.5 \%)$ \\
\hline BMI (kg/m2) & 23.25 [18.65-30.33] \\
\hline Parity & $1[0-6]$ \\
\hline \multicolumn{2}{|l|}{ Menopause } \\
\hline Yes & $23(74.2 \%)$ \\
\hline No & $8(25.8 \%)$ \\
\hline Preoperative CA125 (IU/mL) & $1,833.91[39.2-5,000.00]$ \\
\hline Preoperative albumin (g/dL) & $42.24[28.10-50.40]$ \\
\hline Preoperative platelet count $\left(10^{3} / \mathrm{mm}^{3}\right)$ & 280.55 [133.00-627.00] \\
\hline SUVmax of the primary tumor & 9.94 [3.30-22.10] \\
\hline \multicolumn{2}{|c|}{$\begin{array}{l}\text { Values are presented as median [range] or number (\%). FIGO, } \\
\text { International Federation of Gynecology and Obstetrics; BMI, } \\
\text { body mass index; CA125, cancer antigen 125; SUV } \text { max }_{\text {, maximal }} \\
\text { standard uptake value. }\end{array}$} \\
\hline
\end{tabular}

The median CA125 level was 1,833.91 IU/mL. The median [range] maximum SUV (SUVmax) in the primary tumor was $9.94[3.30-22.10]$.

\section{Surgery-related variables}

The surgery-related variables, including PET score, tumor burden, and surgical complexity, are shown in Table 2. The median [range] of the preoperative PET score was 2 $[0-8]$, and the majority $(n=20 ; 64.5 \%)$ of patients had low PET scores [0-2]. The Eisenkop and PCI scores reflected the tumor burden in abdominopelvic cavities, and the median [range] values were 6.71 [2-12] and 13.71 [2-30], respectively. According to Eisenkop score ranking, 10 $(32.3 \%)$ and $21(67.7 \%)$ of patients had small and large tumor loads, respectively, while 22 (71.0\%), and 9 (29.0\%) had small and large tumor loads in the PCT score system, respectively. The Aletti score reflects surgical complexity,
Table 2 Surgery-related variables $(n=31)$

\begin{tabular}{|c|c|}
\hline Parameter & Value \\
\hline PET score & $2[0-8]$ \\
\hline$\leq 2$ & $20(64.5 \%)$ \\
\hline$>2$ & $11(35.5 \%)$ \\
\hline Eisenkop score & $6.71[2-12]$ \\
\hline Low $(\leq 5)$ & $10(32.3 \%)$ \\
\hline Large $(>5)$ & $21(67.7 \%)$ \\
\hline $\mathrm{PCl}$ score & $13.71[2-30]$ \\
\hline Low ( $\leq 19)$ & 22 (71.0\%) \\
\hline Large $(>19)$ & $9(29.0 \%)$ \\
\hline Aletti score & $5.87[3-12]$ \\
\hline Low [0-3] & $6(19.4 \%)$ \\
\hline Intermediate [4-7] & 18 (58.1\%) \\
\hline High $(\geq 8)$ & $7(22.6 \%)$ \\
\hline \multicolumn{2}{|l|}{ Residual disease } \\
\hline Ro & $11(35.5 \%)$ \\
\hline $\mathrm{R} 1 / \mathrm{R} 2$ & 20 (64.5\%) \\
\hline
\end{tabular}

Values are presented as median [range] or number (\%).

and the median [range] was 5.87 [3-12]. A total of $6(19.4 \%)$, $18(58.1 \%)$, and $7(22.6 \%)$ patients had surgery with low, intermediate, and high complexity, respectively. R0 resection was achieved in $11(35.5 \%)$ patients compared to $20(64.5 \%)$ patients with incomplete resection.

\section{Characteristics of patients with complete resection}

The details of patients with complete resection are shown in Table 3. The median [range] of age was 55 [38-68] years old. The median CA125 level was 1,714.2 IU/mL. For the $\mathrm{PET} / \mathrm{CT}$ scan, the median [range] values of SUVmax and preoperative PET/CT scores were 11.69 [7.4-22.1] and 0.73 [0-4], respectively. Among these patients, 10 (90.91\%) had a low PET score $(\leq 2)$, and only $1(9.09 \%)$ had a high PET score $($ score $=4)$. For tumor burden, the median [range] of Eisenkop score and PCI score was 4.55 [2-8] and 8.18 [2-19], respectively. None of the patients had a low tumor burden in the PCI score ranking system, while 4 had a low tumor burden (36.36\%) in the Eisenkop score ranking system. The surgical complexity score was low in 3 patients (27.27\%), intermediate in 7 (63.64\%), and high 
Table 3 Characteristics of patients with complete resection $(\mathrm{R} 0, \mathrm{n}=11)$

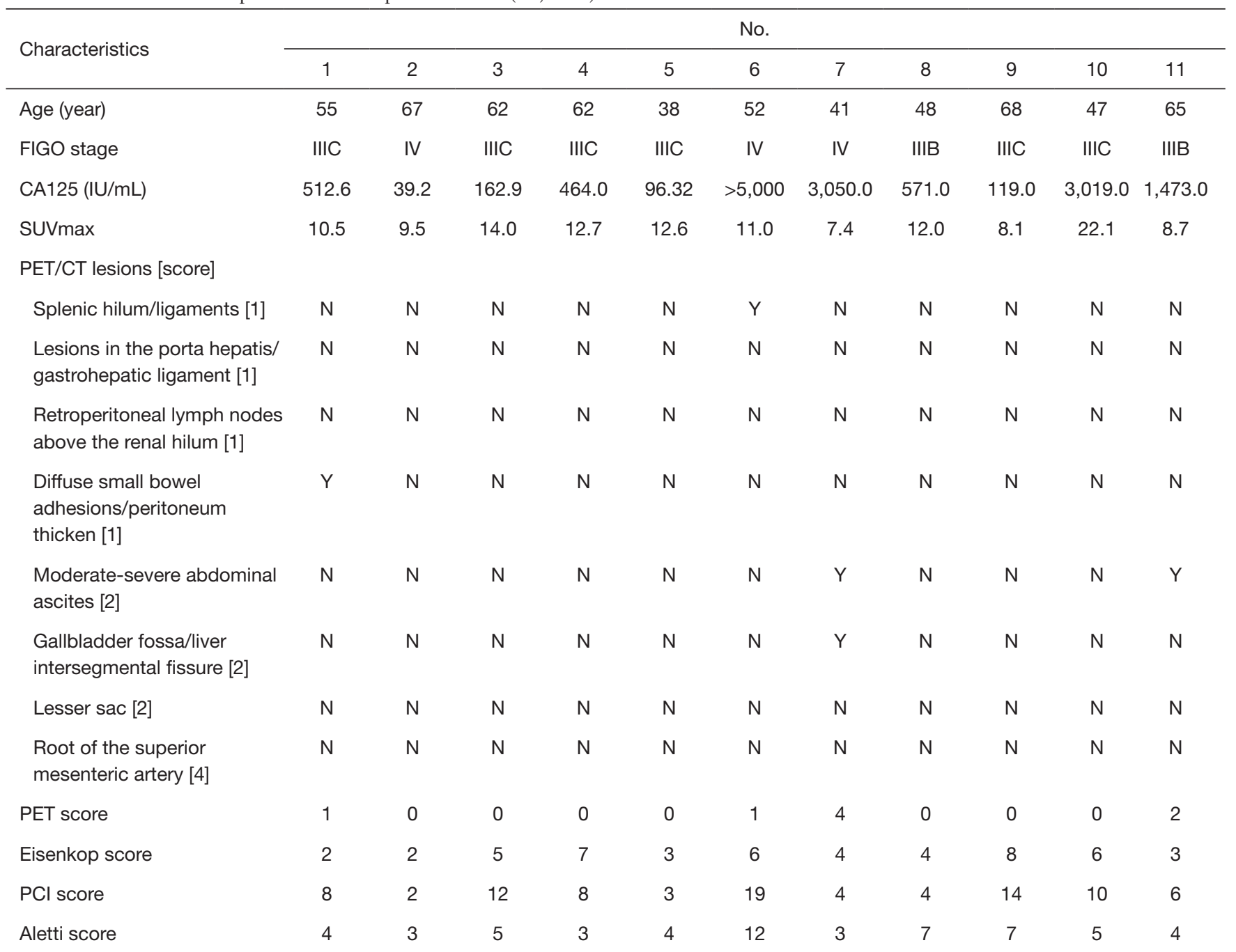

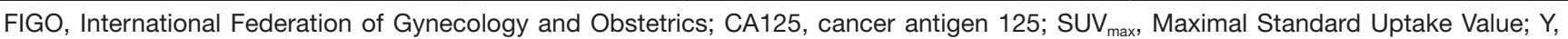
yes; N, no.

in $1(9.09 \%)$. The median [range] surgical complexity score was $5.27[3-12]$.

\section{The correlations between PET score and intraoperative variables}

Tumor burden and surgery complexity are principal factors for residual disease. The preoperative PET score had a significant positive correlation with tumor burden [Eisenkop: $\mathrm{r}=0.603, \mathrm{P}<0.001$; PCI: $\mathrm{r}=0.522, \mathrm{P}=0.003$ (Figure 2)] but not with surgery complexity (Aletti: $\mathrm{r}=0.291$, $\mathrm{P}=0.113$ ). However, neither tumor burden (Eisenkop: $r=-0.272, P=0.139$; PCI: $r=-0.303, P=0.098$ ) nor surgery complexity (Aletti: $\mathrm{r}=-0.036, \mathrm{P}=0.848$ ) had a correlation with SUVmax.

\section{Accuracy of PET score for predicting complete resection}

From Table 4, we found that PET score $(\mathrm{P}=0.008)$, not SUVmax $(\mathrm{P}=0.084)$, was significantly different between the complete and incomplete resection groups. We further dichotomized patients into low and high groups according to the PET score of 2 (19). Patients with complete resection had lower PET scores $(\mathrm{P}=0.046)$ than those with incomplete resection (Figures 3,4). For intraoperative variables, tumor burden (Eisenkop: $\mathrm{P}=0.001$; PCI: $\mathrm{P}=0.002$ ) and not surgery 

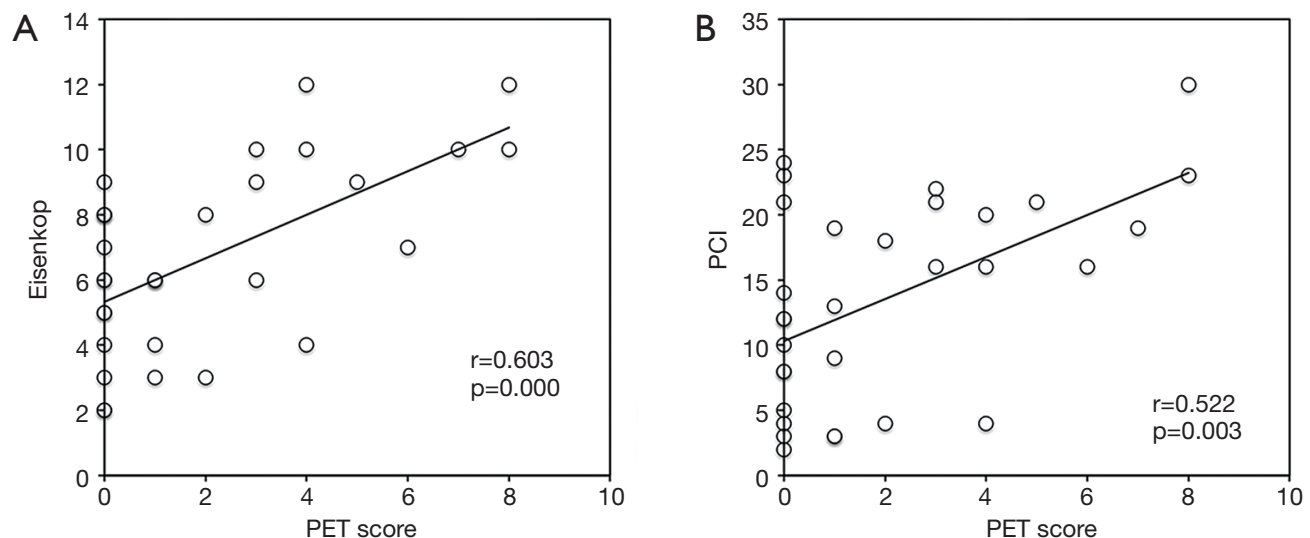

Figure 2 Correlation analysis between PET score and tumor burden. (A) Eisenkop, (B) PCI. The results showed that the preoperative PET score had a significant positive correlation with tumor burden (Eisenkop: $\mathrm{r}=0.603, \mathrm{P}<0.001$; PCI: $\mathrm{r}=0.522$, P=0.003). PCI, peritoneal cancer index; PET, positron emission tomography.

Table 4 The statistical comparison of surgery-related variables between complete and incomplete resection group ( $\mathrm{n}=31$ )

\begin{tabular}{lccc}
\hline Variable & Complete group & Incomplete group & P value \\
\hline SUVmax & $11.69[7.4-22.1]$ & $9.06[3.3-15.8]$ & 0.084 \\
PET score & $0.82[0-4]$ & $2.8[0-8]$ & 0.008 \\
$\leq 2$ & $10(32.26 \%)$ & $10(32.26 \%)$ & 0.046 \\
$>2$ & $1(3.23 \%)$ & $10(32.26 \%)$ & 0.001 \\
Eisenkop score & $4.55[2-8]$ & $7.9[3-12]$ & 0.013 \\
$\leq 5$ & $7(22.58 \%)$ & $17(5.68 \%)$ & 0.002 \\
$>5$ & $4(12.90 \%)$ & $16.75[3-30]$ & 0.012 \\
PCl score & $8.18[2-19]$ & $11(35.48 \%)$ & $9(29.03 \%)$ \\
$\leq 19$ & $11(35.48 \%)$ & $6.20[3-12]$ & 0.356 \\
$>19$ & $0(0 \%)$ & $5.27[3-12]$ &
\end{tabular}

Values are presented as median [range] or number (\%). SUV ${ }_{\max }$, maximal standard uptake value.

complexity (Aletti: $\mathrm{P}=0.356$ ) had statistical significance between these 2 groups. Patients were further dichotomized into low and large tumor loads groups by a score of 5 for Eisenkop, and a score of 19 for PCT according to previous reports $(25,26)$, and it was found that patients with lower tumor burdens had a higher rate of complete resection than those with larger tumor burdens (Eisenkop: $\mathrm{P}=0.013$; PCI: $\mathrm{P}=0.012$ ). The ROC curve was used to assess the ability of the PET score and intraoperative variables to predict complete resection, and the results are shown in Figure 5. We found that PET score and tumor burden were effective for predicting complete resection. The $\mathrm{AUC}_{\mathrm{PET}}, \mathrm{AUC}_{\text {Eisenkop }}$, and $\mathrm{AUC}_{\mathrm{PCI}}$ were 0.797 (95\% CI: 0.633-0.961, $\mathrm{P}=0.01$ ), 0.847 (95\% CI: $0.707-0.988, \mathrm{P}=0.003)$, and 0.811 (95\% CI: $0.653-0.969, \mathrm{P}=0.007)$, respectively. However, surgery complexity did not help predict complete resection, with the $\mathrm{AUC}_{\text {Aletti }}$ being 0.575 (95\% CI: 0.362-0.788, $\mathrm{P}=0.517$ ).

\section{Discussion}

In our study, we demonstrated that a preoperative PET score based on Suidan's radiological model was helpful for 

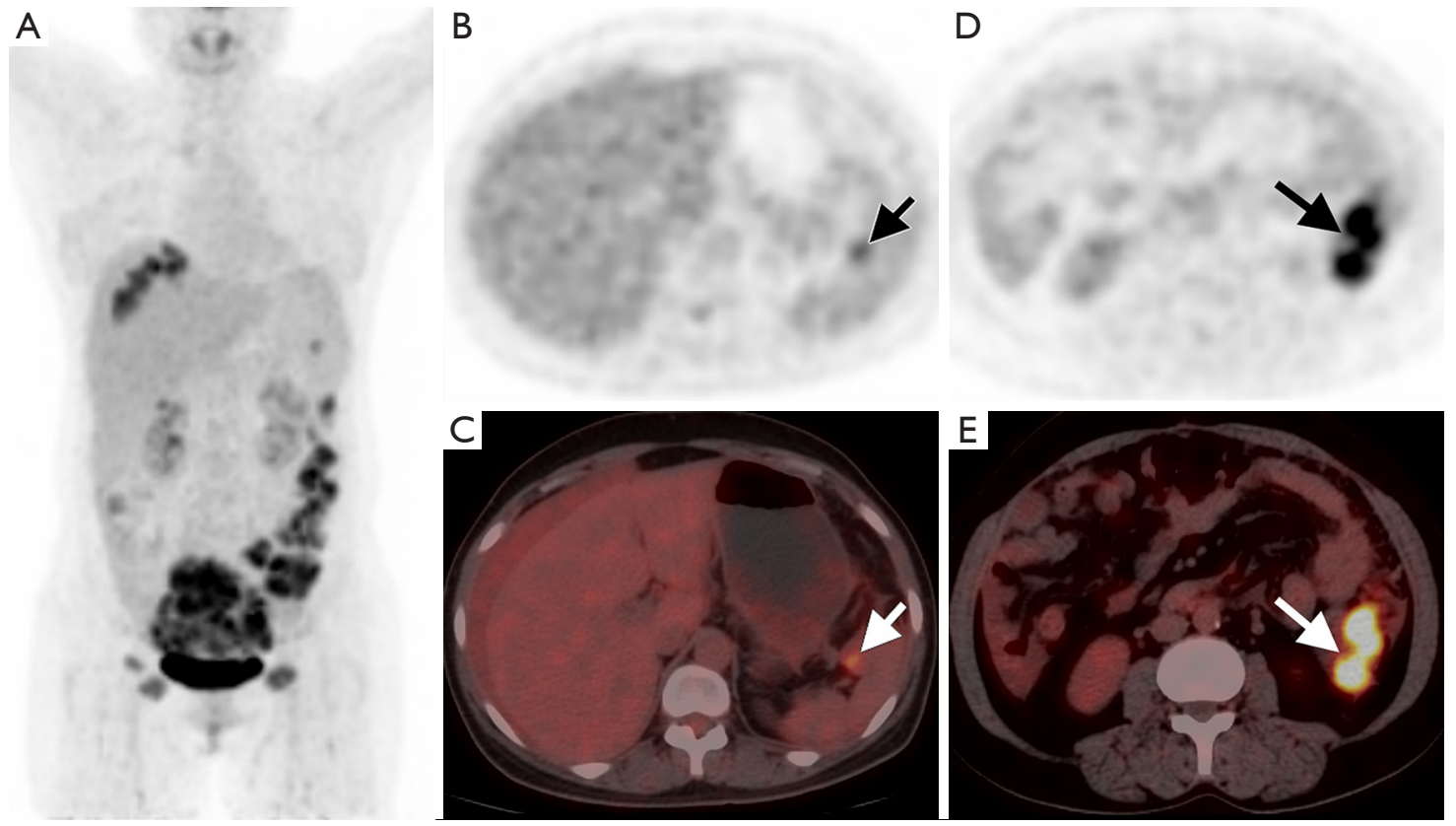

Figure 3 The representative PET and PET/CT fused images in a 52-year suspicious AEOC female. The whole lesions were displayed in the maximum intensity projection image (A). According to preoperative Suidan model, PET/CT scan displayed splenic hilum lesion [score =1, PET (B) and PET/CT fused images (C)], and peritoneal thickening [score =1, PET (D) and PET/CT fused images (E)], and the total PET score was 2. After debulking surgery, high-grade serous ovarian cancer (HGSC) was confirmed by immunohistochemistry, and no gross macroscopic lesion was left. CT, computed tomography; PET, positron emission tomography; AEOC, advanced epithelial ovarian cancer.
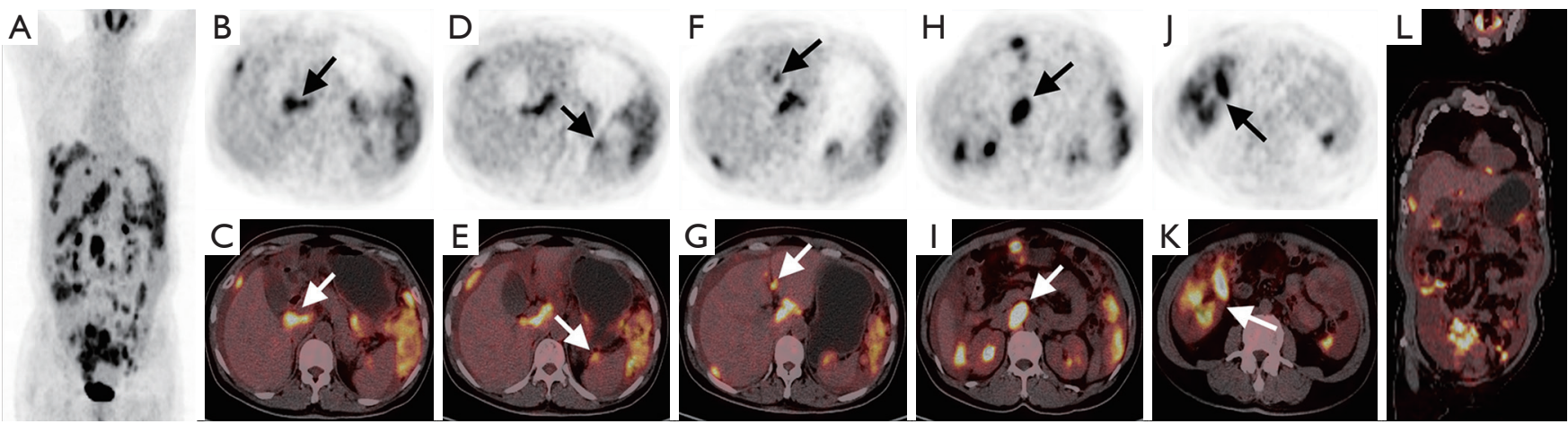

Figure 4 Maximum intensity projection image (A) of preoperative PET/CT scan showed whole lesions in a 52-year suspicious AEOC female. Total PET score was 8 according to Suidan's model, and lesions distributed in the porta hepatis $($ score $=1)$, splenic hilum $($ score $=1$ ), liver intersegmental fissure (score $=2$ ), retroperitoneal lymph nodes above the renal hilum (s), and peritoneal thickening $($ score $=1$ ), with representative figures corresponding to transaxial PET (B,D,F,H,J) and PET/CT fusion images (C,E,G,I,K), respectively. Additionally, moderate-severe abdominal ascites (score $=2$ ) were visible in coronal PET/CT fusion images $(\mathrm{L})$. Complete cytoreduction was not accomplished. The macroscopic residual lesion after surgery was located in the porta hepatis, and the maximal diameter was $0.5 \mathrm{~cm}$. HGSC was pathologically confirmed. CT, computed tomography; PET, positron emission tomography; AEOC, advanced epithelial ovarian cancer. 


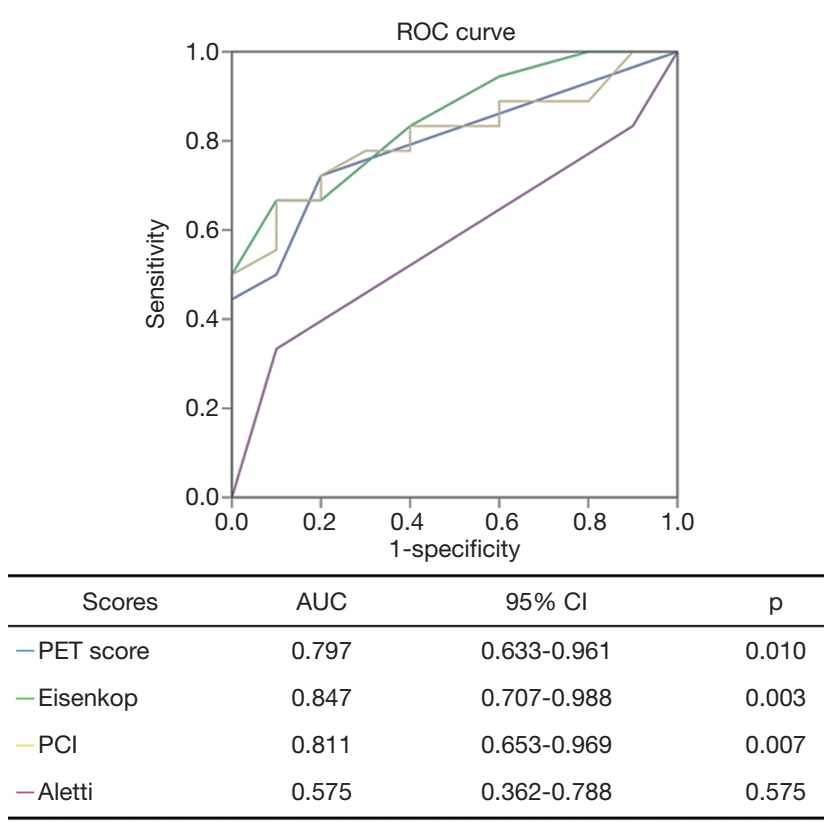

Figure 5 ROC curve analysis of PET score for complete resection. We found that PET score and tumor burden were effective for predicting complete resection. The AUCPET, AUCEisenkop, and AUCPCI were 0.797 (95\% CI: 0.633-0.961, $\mathrm{P}=0.01$ ), 0.847 (95\% CI: 0.707-0.988, P=0.003), and 0.811 (95\% CI: 0.653-0.969, $\mathrm{P}=0.007)$, respectively. However, surgery complexity did not help predict complete resection, and the AUCAletti was 0.575 (95\% CI: 0.362-0.788, $\mathrm{P}=0.517)$. PET, positron emission tomography; ROC, receiver operating characteristic; AUC, area under the curve.

predicting complete resection after cytoreduction in AEOC patients, and the predictive accuracy was 0.797 . Patients with lower PET scores had a low tumor burden, and a higher rate of complete resection.

Residual disease is one of the independent prognostic indicators in OC. Complete cytoreduction has been confirmed to achieve a better prognosis than former satisfactory cytoreduction in AEOC patients, so the definition of optimal debulking has changed to R0 resection over the years (6-9). However, complete tumor resection is not always possible in patients (10). Therefore, several predictive models have been proposed to evaluate residual lesions for the selection of individuals suitable for complete cytoreduction. Compared to laparoscopy, the noninvasive, convenient, and cost-effective method of radiological imaging has shown potential value.

To date, the most comprehensive and clearest quantitative predictive model has been proposed by Suidan et al. (16); it contains 8 radiological criteria from CT scans with a predictive ability (AUC $=0.694$ ) based on the post hoc analysis of a prospective nonrandomized multicenter trial. Although CT scans are widely used, they have low sensitivity $(7-28 \%)$ in the detection of small peritoneal or serosal implants $(20,27,28)$. Numerous studies have reported that PET/CT displayed the best performance in retreatment staging and the evaluation of distant ovarian carcinoma metastases compared with other imaging technologies (ultrasonography, CT and MRI) (20-23) because ${ }^{18} \mathrm{~F}$-FDG PET/CT provides not only anatomical or morphological features but also functional or metabolic characteristics of tumors. The high sensitivity of $74 \%$ for peritoneal surfaces and $56 \%$ for bowel mesentery disease were obtained in PET/CT compared to $47 \%$ and $19 \%$ in CT, respectively (29). Fulham et al. also found that PET/ CT depicted more sites of disease than CT, and treatment was altered in $60 \%$ of patients (30). However, conventional PET/CT parameters, such as SUVmax, mean, standard uptake value $\left(\mathrm{SUV}_{\text {mean }}\right)$, metabolic tumor volume (MTV), and total lesion glycolysis (TLG), reflected the metabolic activity of only 1 lesion or local lesions, not the tumor burden of disease, which determined the ability of complete cytoreduction. Therefore, PET/CT based on the Suidan's predictive model seems more suitable for assessing complete cytoreduction.

Because of the lack of an effective screening method, most women are diagnosed at an advanced stage. The abdominopelvic spread of peritoneal metastasis by hematogenous and implantation metastasis has been found to be the most common in OC patients. The tumor burden in abdominopelvic lesions is not only considered to be an independent prognostic indicator but also one of the most crucial factors in determining whether complete cytoreduction can be achieved $(25,26)$. The PCI score and Eisenkop score are 2 different quantitative methods for evaluating lesion distribution and size throughout the abdominopelvic cavity and were reported by Harmon (26) and Eisenkop (25), respectively. In our study, we first analyzed the correlations between PET score and tumor burden. The results showed that the preoperative PET score had a significant positive correlation with both PCI score $(\mathrm{r}=0.522, \mathrm{P}=0.003)$ and Eisenkop score $(\mathrm{r}=0.603$, $\mathrm{P}<0.001)$, which suggested that PET score could validly and noninvasively reflect the tumor burden to some extent. Surgical complexity is an effective indicator for evaluating the risk of complications based on the complexity and number of surgical procedures (24). However, the PET 
score did not correlate with surgery complexity (Aletti: $\mathrm{r}=0.291, \mathrm{P}=0.113)$.

In our study, we found that patients with complete resection had lower PET scores than those with incomplete resection. The AUC of PET score was 0.797, which indicated high predictive power. This result was consistent with that of the intraoperative tumor burden $\left(\mathrm{AUC}_{\text {Eisenkop }}\right.$ $\left.=0.847, \mathrm{AUC}_{\mathrm{PCI}}=0.811\right)$. Thus, the PET score helps find patients who are eligible for complete surgery. However, surgery complexity failed to predict complete resection, and the $\mathrm{AUC}_{\text {Aletti }}$ was only 0.575. The possible reason was that the number of surgical procedures was not the determinant of residual disease. It is worth noting that up to $50 \%$ of patients with lower PET scores had an incomplete resection in our study even though the result had statistical significance. How to more precisely define these patients would require more candidate enrollment in a later study.

Indeed, the small number of patients enrolled was the main limitation of our study, and was largely a result of only including patients whose surgery was performed by the same surgeon to avoid the possible variability stemming from the differences in the surgical skills of surgeons. Additionally, the expensive cost of a PET/CT scan partly limited patient enrollment. Therefore, more patient enrollment is needed to strengthen our findings. Since the present study was initiated in 2016, long-term prognosis should be analyzed in a further follow-up.

\section{Conclusions}

In conclusion, a preoperative PET score based Suidan's predictive model can noninvasively reflect tumor burden and helps predict complete resection after surgery in AEOC patients, providing a feasible mechanism for identifying patients who are eligible for complete surgery.

\section{Acknowledgments}

We would like to thank Dr. Yuyun Su for help with this study.

Funding: None.

\section{Footnote}

Conflicts of Interest: The authors have no conflicts of interest to declare.

Ethical Statement: This study was approved by the
Committee at Fudan University Shanghai Cancer Center (FUSCC), and informed consent was obtained from all enrolled patients.

Open Access Statement: This is an Open Access article distributed in accordance with the Creative Commons Attribution-NonCommercial-NoDerivs 4.0 International License (CC BY-NC-ND 4.0), which permits the noncommercial replication and distribution of the article with the strict proviso that no changes or edits are made and the original work is properly cited (including links to both the formal publication through the relevant DOI and the license). See: https://creativecommons.org/licenses/by-nc-nd/4.0/.

\section{References}

1. Chen W, Zheng R, Baade PD, Zhang S, Zeng H, Bray F, Jemal A, Yu XQ, He J. Cancer statistics in China, 2015. CA Cancer J Clin 2016;66:115-32.

2. Torre LA, Bray F, Siegel RL, Ferlay J, Lortet-Tieulent J, Jemal A. Global cancer statistics, 2012. CA Cancer J Clin 2015;65:87-108.

3. Bristow RE, Chang J, Ziogas A, Anton-Culver H. Adherence to treatment guidelines for ovarian cancer as a measure of quality care. Obstet Gynecol 2013;121:1226-34.

4. Morgan RJ Jr, Alvarez RD, Armstrong DK, Burger RA, Chen LM, Copeland L, Crispens MA, Gershenson DM, Gray HJ, Hakam A, Havrilesky LJ, Johnston C, Lele S, Martin L, Matulonis UA, O'Malley DM, Penson RT, Powell MA, Remmenga SW, Sabbatini P, Santoso JT, Schink JC, Teng N, Werner TL, Dwyer MA, Hughes $\mathrm{M}$; National comprehensive cancer networks. Ovarian cancer, version 2.2013. J Natl Compr Canc Netw 2013;11:1199-209.

5. Berek JS, Crum C, Friedlander M. Cancer of the ovary, fallopian tube, and peritoneum. Int J Gynaecol Obstet 2015;131 Suppl 2:S111-22.

6. Aletti GD, Dowdy SC, Gostout BS, Jones MB, Stanhope CR, Wilson TO, Podratz KC, Cliby WA. Aggressive surgical effort and improved survival in advanced-stage ovarian cancer. Obstet Gynecol 2006;107:77-85.

7. Chang SJ, Bristow RE, Ryu HS. Impact of complete cytoreduction leaving no gross residual disease associated with radical cytoreductive surgical procedures on survival in advanced ovarian cancer. Ann Surg Oncol 2012;19:4059-67.

8. Chi DS, Eisenhauer EL, Lang J, Huh J, Haddad L, Abu- 
Rustum NR, Sonoda Y, Levine DA, Hensley M, Barakat RR. What is the optimal goal of primary cytoreductive surgery for bulky stage IIIC epithelial ovarian carcinoma (EOC)? Gynecol Oncol 2006;103:559-64.

9. Peiretti M, Zanagnolo V, Aletti GD, Bocciolone L, Colombo N, Landoni F, Minig L, Biffi R, Radice D, Maggioni A. Role of maximal primary cytoreductive surgery in patients with advanced epithelial ovarian and tubal cancer: Surgical and oncological outcomes. Single institution experience. Gynecol Oncol 2010;119:259-64.

10. Aletti GD, Gostout BS, Podratz KC, Cliby WA. Ovarian cancer surgical resectability: relative impact of disease, patient status, and surgeon. Gynecol Oncol 2006;100:33-7.

11. Jung DC, Kang S, Kim SC, Kim JW, Nam JH, Ryu SY, Seong SJ, Kim BG. Use of complex surgical procedures, patterns of tumor spread, and CA-125 predicts a risk of incomplete cytoreduction: a Korean Gynecologic Oncology Group study (KGOG-3022). Gynecol Oncol 2013;131:336-40.

12. MacKintosh ML, Rahim R, Rajashanker B, Swindell R, Kirmani BH, Hunt J, Brockbank E, Barton DP, Clayton RD. CT scan does not predict optimal debulking in stage III-IV epithelial ovarian cancer: a multicentre validation study. J Obstet Gynaecol 2014;34:424-8.

13. Shim SH, Lee SJ, Kim SO, Kim SN, Kim DY, Lee JJ, Kim JH, Kim YM, Kim YT, Nam JH. Nomogram for predicting incomplete cytoreduction in advanced ovarian cancer patients. Gynecol Oncol 2015;136:30-6.

14. Suidan RS, Ramirez PT, Sarasohn DM, Teitcher JB, Mironov S, Iyer RB, Zhou Q, Iasonos A, Paul H, Hosaka M, Aghajanian CA, Leitao MM Jr, Gardner GJ, AbuRustum NR, Sonoda Y, Levine DA, Hricak H, Chi DS. A Multicenter Prospective Trial Evaluating the Ability of Preoperative Computed Tomography Scan and Serum CA-125 to Predict Suboptimal Cytoreduction at Primary Debulking Surgery for Advanced Ovarian, Fallopian Tube, and Peritoneal Cancer. Gynecol Oncol 2014;134:455-61.

15. Fanfani F, Monterossi G, Fagotti A, Gallotta V, Costantini B, Vizzielli G, Petrillo M, Carbone MV, Scambia G. Positron Emission Tomography-Laparoscopy Based Method in the Prediction of Complete Cytoreduction in Platinum-Sensitive Recurrent Ovarian Cancer. Ann Surg Oncol 2015;22:649-54.

16. Suidan RS, Ramirez PT, Sarasohn DM, Teitcher JB, Iyer RB, Zhou Q, Iasonos A, Denesopolis J, Zivanovic O, Long Roche KC, Sonoda Y, Coleman RL, Abu-Rustum NR, Hricak H, Chi DS. A multicenter assessment of the ability of preoperative computed tomography scan and CA-125 to predict gross residual disease at primary debulking for advanced epithelial ovarian cancer. Gynecol Oncol 2017;145:27-31.

17. Risum S, Høgdall C, Loft A, Berthelsen AK, Høgdall E, Nedergaard L, Lundvall L, Engelholm SA. Prediction of suboptimal primary cytoreduction in primary ovarian cancer with combined positron emission tomography/ computed tomography--a prospective study. Gynecol Oncol 2008;108:265-70.

18. Shim SH, Kim DY, Seo MJ, Lee SW, Park JY, Lee JJ, Kim JH, Kim YM, Kim YT, Nam JH. Preoperative fluorine 18 fluorodeoxyglucose tumoral uptake ratio between upper and lower abdomen in primary advanced-stage ovarian cancer. Int J Gynecol Cancer 2013;23:1383-92.

19. Feng Z, Wen H, Jiang Z, Liu S, Ju X, Chen X, Xia L, Xu J, $\mathrm{Bi} \mathrm{R}, \mathrm{Wu} \mathrm{X}$. A triage strategy in advanced ovarian cancer management based on multiple predictive models for R0 resection: a prospective cohort study. J Gynecol Oncol 2018;29:e65.

20. Kyriazi S, Kaye SB, deSouza NM. Imaging ovarian cancer and peritoneal metastases--current and emerging techniques. Nat Rev Clin Oncol 2010;7:381-93.

21. Kitajima K, Murakami K, Yamasaki E, Kaji Y, Fukasawa I, Inaba N, Sugimura K. Diagnostic accuracy of integrated FDG-PET/contrast-enhanced CT in staging ovarian cancer: comparison with enhanced CT. Eur J Nucl Med Mol Imaging 2008;35:1912-20.

22. Nam EJ, Yun MJ, Oh YT, Kim JW, Kim JH, Kim S, Jung YW, Kim SW, Kim YT. Diagnosis and staging of primary ovarian cancer: correlation between PET/CT, Doppler US, and CT or MRI. Gynecol Oncol 2010;116:389-94.

23. Yuan Y, Gu ZX, Tao XF, Liu SY. Computer tomography, magnetic resonance imaging, and positron emission tomography or positron emission tomography/computer tomography for detection of metastatic lymph nodes in patients with ovarian cancer: a meta-analysis. Eur J Radiol 2012;81:1002-6.

24. Aletti GD, Dowdy SC, Podratz KC, Cliby WA. Relationship among surgical complexity, short-term morbidity, and overall survival in primary surgery for advanced ovarian cancer. Am J Obstet Gynecol 2007;197:676.e1-7.

25. Eisenkop SM, Spirtos NM, Friedman RL, Lin WC, Pisani AL, Perticucci S. Relative influences of tumor volume before surgery and the cytoreductive outcome on survival for patients with advanced ovarian cancer: a prospective study. Gynecol Oncol 2003;90:390-6.

26. Harmon RL, Sugarbaker PH. Prognostic indicators in 
peritoneal carcinomatosis from gastrointestinal cancer. Int Semin Surg Oncol 2005;2:3.

27. Kurtz AB, Tsimikas JV, Tempany CM, Hamper UM, Arger PH, Bree RL, Wechsler RJ, Francis IR, Kuhlman JE, Siegelman ES, Mitchell DG, Silverman SG, Brown DL, Sheth S, Coleman BG, Ellis JH, Kurman RJ, Caudry DJ, McNeil BJ. Diagnosis and staging of ovarian cancer: comparative values of Doppler and conventional US, CT, and MR imaging correlated with surgery and histopathologic analysis-report of the Radiology Diagnostic Oncology Group. Radiology. 1999;212:19-27.

28. Coakley FV, Choi PH, Gougoutas CA, Pothuri B, Venkatraman E, Chi D, Bergman A, Hricak H. Peritoneal metastases: detection with spiral CT in patients with ovarian cancer. Radiology 2002;223:495-9.

29. Hynninen J, Kemppainen J, Lavonius M, Virtanen J, Matomäki J, Oksa S, Carpén O, Grénman S, Seppänen M, Auranen A. A prospective comparison of integrated FDGPET/contrast-enhanced CT and contrast-enhanced CT for pretreatment imaging of advanced epithelial ovarian cancer. Gynecol Oncol 2013;131:389-94.

30. Fulham MJ, Carter J, Baldey A, Hicks RJ, Ramshaw JE, Gibson M. The impact of PETCT in suspected recurrent ovarian cancer: a prospective multi-centre study as part of the Australian PET Data Collection Project. Gynecol Oncol 2009;112:462-8.
Cite this article as: $\mathrm{Gu} \mathrm{B}, \mathrm{Xia} \mathrm{L}, \mathrm{Ge} \mathrm{H}$, Liu S. Preoperative $\mathrm{PET} / \mathrm{CT}$ score can predict complete resection in advanced epithelial ovarian cancer: a prospective study. Quant Imaging Med Surg 2020;10(3):743-753. doi: 10.21037/qims.2020.02.19 
Supplementary

\begin{tabular}{|c|c|}
\hline $\begin{array}{l}\text { Surgical complexity scoring sys } \\
\text { complexity and number of surg } \\
\text { performed }\end{array}$ & $\begin{array}{l}\text { ed upon } \\
\text { edures }\end{array}$ \\
\hline Procedure & Points \\
\hline TH-BSO & 1 \\
\hline Omentectomy & 1 \\
\hline Pelvic lymphadenectomy & 1 \\
\hline Paraaortic lymphadenectomy & 1 \\
\hline Pelvic peritoneum stripping & 1 \\
\hline $\begin{array}{l}\text { Abdominal peritoneum } \\
\text { stripping }\end{array}$ & 1 \\
\hline $\begin{array}{l}\text { Rectosigmoidectomy_T-T } \\
\text { anastomosis }\end{array}$ & 3 \\
\hline Large bowel resection & 2 \\
\hline Diaphragm stripping/resection & 2 \\
\hline Splenectomy & 2 \\
\hline Liver resection/s & 2 \\
\hline Small bowel resection/s & 1 \\
\hline
\end{tabular}

Figure S1 Aletti scoring system for surgical complexity (24). THBSO, total hysterectomy-bilateral salpingo-oophorectomy. 


\begin{tabular}{|c|c|}
\hline Anatomic regions & Numerical rank \\
\hline \multicolumn{2}{|l|}{ Right upper quadrant (diaphragm, right hepatic surface, crural area, portal area, peritoneum adjacent to right kidney, and duodenum } \\
\hline No visible disease & 0 \\
\hline Metastatic implants and/or confluent disease involving $\leq 50 \%$ surface area of diaphragm & 1 \\
\hline Metastatic implants and/or confluent disease involving $>50 \%$ surface area of diaphragm & 2 \\
\hline $\begin{array}{l}\text { Any confluent diaphragm disease with invasion into muscle or contiguous involvement of the bare area and/or surface of liver, } \\
\text { peritoneum adjacent to right kidney and duodenum, or portal region }{ }^{\mathrm{a}}\end{array}$ & 3 \\
\hline \multicolumn{2}{|l|}{$\begin{array}{l}\text { Left upper quadrant (omentum, gastro-colic ligament, spleen, stomach, transverse colon, splenic flexure of colon, left hepatic } \\
\text { surface, and left diaphragm) }\end{array}$} \\
\hline No visible disease & 0 \\
\hline Involvement of infra-colic omentum & 1 \\
\hline Involvement of infra-colic omentum and gastro-colic ligament & 2 \\
\hline $\begin{array}{l}\text { Involvement of infra-colic omentum and/or gastro-colic ligament and contiguous involvement of spleen, stomach, transverse } \\
\text { colon, splenic flexure of colon, left diaphragm, or liver surface }{ }^{b}\end{array}$ & 3 \\
\hline \multicolumn{2}{|l|}{ Pelvis (reproductive organs, pelvic peritoneum, cul-de-sac, bladder peritoneum, recto-sigmoid) } \\
\hline Adnexal disease only & 0 \\
\hline $\begin{array}{l}\text { Extensive confuent disease involving pelvic peritoneal surfaces, including the cul-de-sac, bladder peritoneum, and/or } \\
\text { recto-sigmoid serosa }\end{array}$ & 2 \\
\hline Bulky disease encasing much of pelvis, including the cul-de-sac and recto-sigmoid colon & 3 \\
\hline \multicolumn{2}{|l|}{ Retroperitoneum (retroperitoneal nodes distal to crura) ${ }^{c}$} \\
\hline No positive nodes and/or microscopic positive & 0 \\
\hline Grossly positive nodes, largest $\leq 1 \mathrm{~cm}$ & 1 \\
\hline Grossly positive nodes $>1 \mathrm{~cm}$ & 2 \\
\hline Confuent bulky positive retroperitoneal nodal disease & 3 \\
\hline \multicolumn{2}{|l|}{ Central abdomen (small intestines, ascending and descending colon, intestinal mesentery, lateral pericolic gutters, anterior abdomen) } \\
\hline No visible disease (excludes pelvis, omentum, diaphragm, and hepatic surfaces) & 0 \\
\hline$\leq 50$ metastatic implants & 1 \\
\hline$>50$ metastatic implants & 2 \\
\hline Metastatic implants contiguous with bulky disease involving bowel and/or mesentery ${ }^{d}$ & 3 \\
\hline
\end{tabular}

${ }^{a}$ Excludes disease involving the hepatic surface and/or portal region that is not contiguous with diaphragm disease.

${ }^{b}$ Excludes disease involving spleen, stomach, hepatic surface, diaphragmatic surface, or colon that is not contiguous with omental and/or gastro-colic disease.

${ }^{\mathrm{C}}$ Retroperitoneal lymph node dissection required unless retroperitoneal nodes and adjacent structures replaced and/or encased by biopsy-proven metastatic disease.

${ }^{d}$ Excludes gross intestinal and colonic metastases that are contiguous with omental or pelvic disease.

Figure S2 Ranking of the extent of disease at anatomic regions for tumor burden according to the Eisenkop scoring criterion (25).

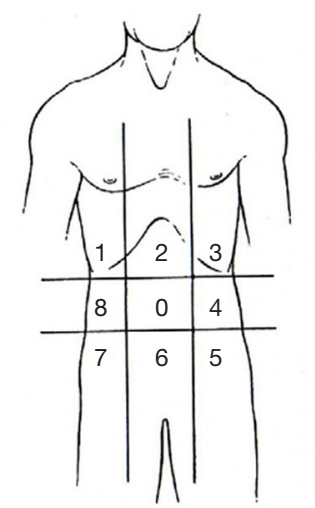

$\mathrm{PCl}$

\begin{tabular}{|c|c|c|}
\hline & gions & Lesion size \\
\hline 0 & Central & \\
\hline 1 & Right Upper & \\
\hline 2 & Epigastrium & \\
\hline 3 & Left Upper & \\
\hline 4 & Left Flank & \\
\hline 5 & Left Lower & \\
\hline 6 & Pelvis & \\
\hline 7 & Right Lower & \\
\hline 8 & Right Flank & \\
\hline & Upper Jejunum & \\
\hline & Lower Jejunum & \\
\hline & Upper lleum & \\
\hline & Lower lleum & \\
\hline & $\mathrm{Cl}$ & \\
\hline
\end{tabular}

Lesion Size Score

LS 0 No tumor seen

LS 1 Tumor up to $0.5 \mathrm{~cm}$

LS 2 Tumor up to $5.0 \mathrm{~cm}$

LS 3 Tumor $>5.0 \mathrm{~cm}$ or confuence or confuence

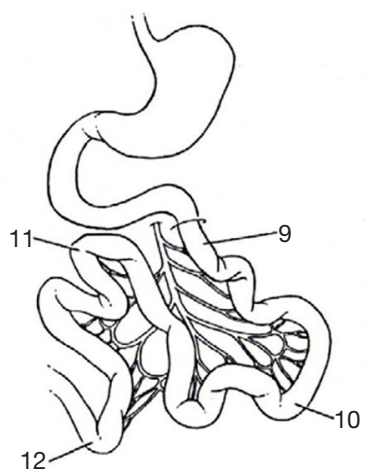

Figure S3 Peritoneal cancer index (PCI) for tumor burden (26). 